\title{
Up-conversion luminescence coupled to plasmonic gold nanorods for light harvesting and hydrogen production
}

\author{
H. AlGhamdi ${ }^{a}$, B. Katsiev ${ }^{\text {a }}$, A.K. Wahab ${ }^{a}$, J. Llorca ${ }^{b}$, and H. Idriss ${ }^{a}{ }^{a_{*}}$
}

The conversion of infra-red to visible-light, the so called "upconversion luminescence", and its use for $\mathrm{H}_{2}$ production allowing for a larger fraction of sun light on earth to be used is one of the most important light harvesting aims. We have prepared, characterized and tested a tri-functional material composed of an up-converter ( $\mathrm{NaYF}_{4}-\mathrm{Yb}-\mathrm{Tm}$ ), plasmonic gold nanorods (Au NRs), and a CdS semiconductor. Tests with gas phase methanol/ $\mathrm{O}_{2}$ resulted in the production of $\mathrm{H}_{2}$ and $\mathrm{CO}_{2}$ upon excitation with a $980 \mathrm{~nm}$ IR light. Equally important, these products were observed (although with a third of the value obtained by the ternary system) for the binary system ( $\mathrm{NaYF}_{4}-\mathrm{Yb}-\mathrm{Tm} / \mathrm{Au} \mathrm{NRs}$ ); wihtout the $\mathrm{CdS}$ semiconductor. This is the first time that $\mathrm{H}_{2}$ was made photocatalytically using plasmonic $\mathrm{Au}$ nanoparticles upon initial excitation with infra-red light and is attributed to the upconversion process.

The low light flux and weak energy density of sunlight on earth (ca. $1 \mathrm{~kW} / \mathrm{m}^{2}$ ), half of which is composed of infra-red light, are two limiting factors affecting the progress of solar-driven processes. While considerable progress has been made in photovoltaic solar cells, their still relatively high cost makes them non-competitive, compared to fossil fuel, for energy intensive systems (such as those used in chemical and transport industries). Photo-catalytic materials are to date far less efficient than photovoltaics and are thus unpractical for energy harvesting. Many limiting factors are behind this lack of progress. Most active semiconductor materials are either unstable in water ${ }^{1,2,3}$ or do not possess the electronic band edge requirements ${ }^{4}$ for the redox reaction needed for water splitting. Actually, because of thermodynamics, most of stable semiconductors have large band gaps (typically $>3 \mathrm{eV}$ ), such as $\mathrm{TiO}_{2}, \mathrm{SrTiO}_{3}$ and $\mathrm{GaN}$ limiting their use to specific small scale applications, which cannot compete with fossil fuel based processes ${ }^{5}$. Over the last two decades, considerable efforts were undertaken to address these; such as anion doping to decrease the wide band gap of semiconductors ${ }^{6,7,8}$ multi-phase semiconductors ${ }^{9,10,11,12}$, plasmonic metals to improve light harvesting ${ }^{13,14,15}$ and specific 3D-archetacture to increase light harvesting and decrease charge carriers' recombination rates $^{16,17,18,19}$, with limited success. One promising alternative to address the wide band gap semiconductors issue is to change the

\footnotetext{
${ }^{\mathrm{a}}$ Corporate Research \& Development (CRD), Saudi Basic Industries
}

Corporation (SABIC) KAUST, Thuwal 23955-6900, Saudi Arabia

${ }^{b}$ Institute of Energy Technologies, Department of Chemical Engineering and Barcelona Research Center in Multiscale Science and Engineering. Universitat Politècnica de Catalunya, EEBE, Barcelona, Spain light frequency rather than changing the materials energy gap and thus allow their use, since they are stable in water, for $\mathrm{H}_{2}$ generation. In that regard, up-conversion (UC) luminescence is attractive. However, the very weak efficiency of this system makes this process so far of marginal importance. A second requirement is thus needed and it is light amplification. A possible approach for that is the use of a plasmonic system poised to enhance the local electric field by many orders of magnitudes ${ }^{20}$ at the interface of the UC material, thus in theory an efficient ternary (UC-plasmoniccatalyst material) system can be made. UC luminescence is the sequential absorption of two or more photons and can take place through a number of pathways, which have been discussed in various reviews and articles ${ }^{21,22,23,24,25,26,27}$. Since Auzel and coworkers ${ }^{28}$ reported their pioneering work on lanthanide-based UC processes most materials studied are based on lanthanide ions, $\mathrm{Ln}^{\mathrm{x}}$, such as Erbium $\left(\mathrm{Er}^{3+}\right)$, Holium $\left(\mathrm{Ho}^{3+}\right)$, and Thuluim $\left(\mathrm{Tm}^{3+}\right)$ in an inorganic host containing Ytterbium $\left(\mathrm{Yb}^{3+}\right)$.

In this work, we have used an inorganic host material, $\mathrm{NaYF}_{4}$, in which $\mathrm{Yb}$ cations are dispersed: $\mathrm{NaYF}_{4}-\mathrm{Yb}$. This results in light absorption at $980 \mathrm{~nm}$ which when doped with Tm cations an upconverter emission takes place at difference wavelengths. The absorbance at $980 \mathrm{~nm}$ and the emissions, need to be tuned with the semiconductor band gap as well as with the plasmon resonance energy, to fulfil the compositional and structural requirements. We have prepared the up-conversion material $\left(\mathrm{NaYF}_{4}-\mathrm{Yb}, \mathrm{Tm}\right.$ ) with $\mathrm{Tm}$ at. $\%=1.67 \%$ (with respect to $\mathrm{Y}$ and $\mathrm{Yb}$ ) (figures 1 and S1A). Figures S1B and S1C show the response of the UC material to light frequency. We have prepared a few materials with different Tm\%; the one reported here gave the best performance.

Figure $1 \mathrm{~A}$ presents the $\mathrm{NaY}(\mathrm{Yb}) \mathrm{F}_{4}: \mathrm{Tm}$ which is composed of individual crystallites of about $150-250 \mathrm{~nm}$ in size. EDX analyses show the presence of $\mathrm{F}, \mathrm{Na}, \mathrm{Yb}$ and $\mathrm{Y}$ (the $\mathrm{Cu}$ signal comes from the TEM grid); The crystalline nature of the $\mathrm{NaY}_{(\mathrm{Yb}) \mathrm{F}_{4}}$ is shown in Figure 1B. $\mathrm{Au} / \mathrm{CdS} / \mathrm{NaY}\left(\mathrm{Yb} \mathrm{F}_{4}: \mathrm{Tm}\right.$ is presented in Figures $1 \mathrm{C}-1 \mathrm{~F}$. The large particles correspond to $\mathrm{NaY}(\mathrm{Yb}) \mathrm{F}_{4}$, whereas the smaller ones are CdS. In addition, Au nanorods are also present in contact with CdS nanoparticles. There exists an intimate contact between all the phases present. Figures $1 \mathrm{C}$ and $1 \mathrm{D}$ correspond to two images recorded in TEM and STEM-HAADF modes, respectively, of the same area of the sample. 

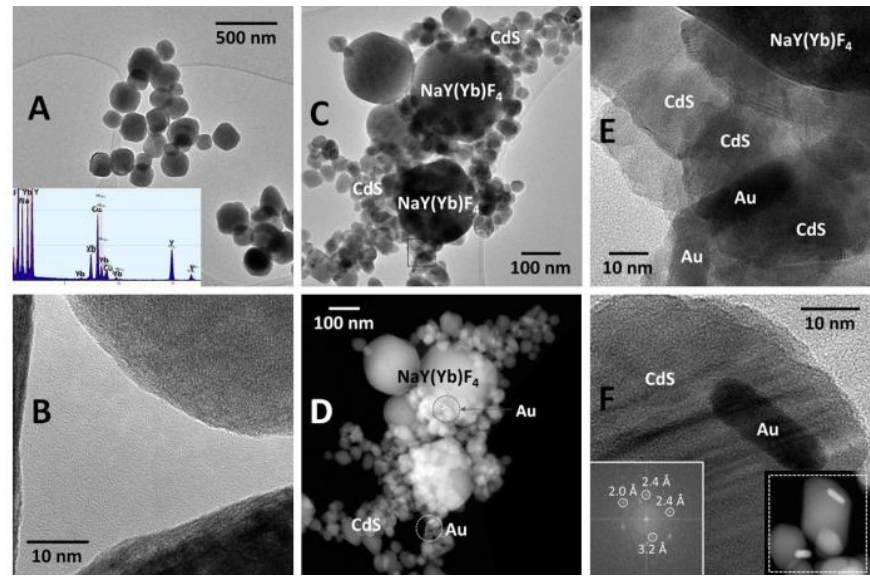

Figure 1.

TEM and HRTEM of NaY(Yb)F $F_{4}: T_{m}$ and Au/CdS/ NaYF 4 (Yb):Tm. A. TEM of $\mathrm{NaYF}_{4}(\mathrm{Yb}): \mathrm{Tm}$; B. HRTEM of NaYF 4 (Yb):Tm; C. Au/CdS/ NaYF 4 (Yb):Tm; D. STEM-HAADF of C.; E. HRTEM of the square area of C.; F. HRTEM, STEM and FFT of $\mathrm{Au} / \mathrm{CdS}$ nanoparticles.

A good contact exists between $\mathrm{NaY}(\mathrm{Yb}) \mathrm{F}_{4}$ and Au-CdS. A HRTEM image corresponding to the square depicted in Figure $1 \mathrm{C}$ is shown in Figure 1E. The crystallinity and good contact between the different phases is clear. The bottom right inset in Figure $1 \mathrm{~F}$ shows another STEM-HAADF image exhibiting $\mathrm{CdS}$ particles and $\mathrm{Au}$ nanorods. The upper part of the image in the white square is shown in HRTEM mode in Figure 1F. The bottom left of Figure $1 \mathrm{~F}$ presents an FT image with spots at $3.2 \AA$, corresponding to the (101) crystallographic planes of the CdS support particle while those at 2.4 and $2.0 \AA$ correspond to the (111) and (200) crystallographic planes of the metallic $\mathrm{Au}$ nanorod, which is oriented along the [110] crystallographic direction. To summarize, the $\mathrm{Au}-\mathrm{CdS}-\mathrm{NaY}(\mathrm{Yb}) \mathrm{F}_{4}$ sample is constituted by $\mathrm{NaY}(\mathrm{Yb}) \mathrm{F}_{4}$ crystallites of 150-250 nm surrounded by CdS nanoparticles of 40$80 \mathrm{~nm}$. Some of the CdS nanoparticles are decorated by Au metal nanorods. There is a good contact between the different phases present in the sample and no agglomeration or segregation of a single phase occurs.

The system was excited with a femto second laser (Libra F-HE, Coherent) which has a maximum power of $4 \mathrm{~W} / \mathrm{cm}^{2}$ in the IR region. As seen in figure S1 the up-conversion emissions of light at $800 \mathrm{~nm}$ and $477 \mathrm{~nm}$ are produced upon excitation with $980 \mathrm{~nm}$ light. In order to test this we have prepared a CdS semiconductor (that absorbs light at around $500 \mathrm{~nm}$ ) on top of which we have put Au nanorods $(\mathrm{d}=10 \mathrm{~nm}$ and $\mathrm{L}=41 \mathrm{~nm}, 0.25 \mathrm{wt}$. \%, the remaining is CdS; see methodology section). The CdS was prepared and characterized following a previous work ${ }^{2}$. We have measured the Au nano-rods for their particular plasmon resonance response in the IR and Visible (figure 2) light range. This has resulted in extending the Au plasmon energy into the IR region due to both the transversal and longitudinal plasmons ${ }^{29,30}$ ). This wide spectral range, most likely due to light scattering, was in our favor, as it coincided with the absorbance edge of the up-converter (980 nm); and this is needed to enhance light adsorption which in turn is poised to enhance light emission. Figure 2 shows that the presence of Au nanorods on top of CdS has resulted in light absorption above $800 \mathrm{~nm}$, extending up to $1000 \mathrm{~nm}$; thus covering the absorption edge of the UC material.

$\mathrm{NaYF}_{4}(\mathrm{Yb}): \mathrm{Tm}$ crystals have a gagarinite group structure with five bands of $2 \mathrm{~A}_{\mathrm{g}}+3 \mathrm{E}_{2 \mathrm{~g}} 31,32,33$, Figure 3 . The most enhanced phonon modes were at $253.4,303.5,366.2,495.4$ and $632.6 \mathrm{~cm}^{-1}$, these phonons modes are similar to un-doped $\mathrm{NaYF}_{4}$ samples. The contribution of Tm was not observed due to its low concentration.

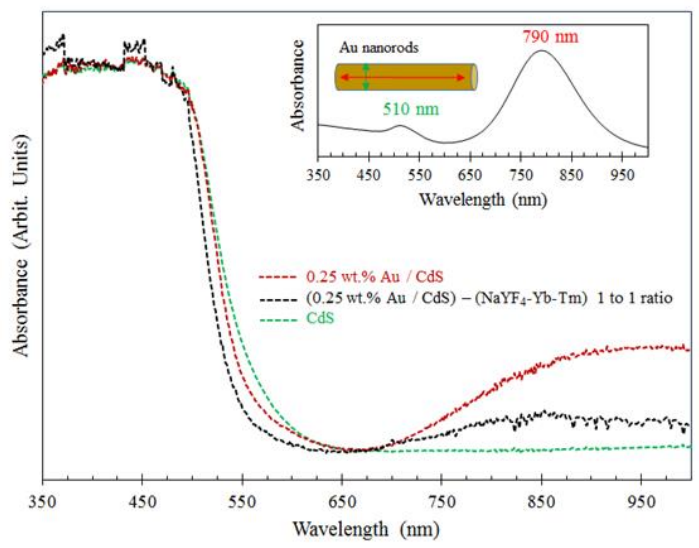

Figure 2

UV-Vis absorbance of $\mathrm{CdS}, 0.25 \mathrm{wt} . \% \mathrm{Au} / \mathrm{CdS}$ before reaction and $0.25 \mathrm{wt}$. $\% \mathrm{Au} / \mathrm{CdS} / \mathrm{UC}$ after reaction ( $\mathrm{CdS}$ to the upconverter $\left(\mathrm{NaYF}_{4}-\mathrm{Yb}-\mathrm{Tm}\right)$ ratio is 1 to 1). Inset: UV-Vis absorbance of colloidal gold nanorods in water. Au NRs: $10 \mathrm{~nm}(\mathrm{~d})$ and $41 \mathrm{~nm}(\mathrm{~L})$.

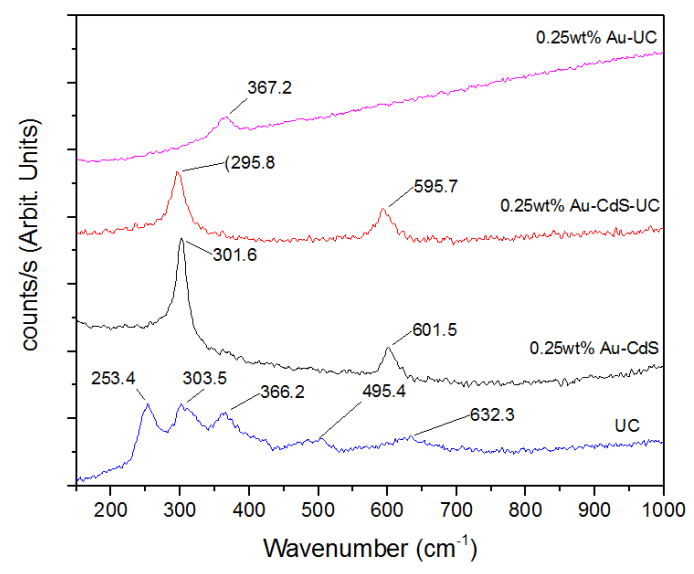

Figure 3

Raman shifts spectra of $\mathrm{NaYF}_{4}(\mathrm{Yb}): \mathrm{Tm}, \mathrm{Au} / \mathrm{CdS} / \mathrm{NaYF}_{4}(\mathrm{Yb}): \mathrm{Tm}$ and $\mathrm{Au} / \mathrm{CdS}$

The electron phonon coupling in these lattices takes place at relatively low energy phonon modes. Due to this property, $\mathrm{NaYF}_{4}$ is considered the best host for up conversion with different rare earth ions ${ }^{34}$. The Raman spectrum of Au-CdS shows two phonon vibrational modes, first and second order LO modes at 301.6 and $601.5 \mathrm{~cm}^{-135}$. A shift of $5.8 \mathrm{~cm}^{-1}$ in the case of Au-CdS $/ \mathrm{NaYF}_{4} / \mathrm{Yb}: \mathrm{Tm}$ is noticed when compared to Au-CdS.

We have excited the complete UC catalyst with $980 \mathrm{~nm}$ light (the absorbance edge of the UC) in the presence of gas phase methanol/air. Then we have monitored both $\mathrm{H}_{2}$ and $\mathrm{CO}_{2}$ production. CdS can only work as a semiconductor photo-catalyst upon excitation with visible light range and is therefore inactive when excited with $980 \mathrm{~nm}$ light. The needed wavelength is provided by the up-converter material since a fraction of the $980 \mathrm{~nm}$ light is converted to $802 \mathrm{~nm}$ and $477 \mathrm{~nm}$ which excite both the $\mathrm{Au}$ nano-rods and the $\mathrm{CdS}$, respectively. The results were positive, in other words $\mathrm{H}_{2}$ and $\mathrm{CO}_{2}$ were detected and monitored (figure 4).

The photocatalytic methanol reaction in the presence of $\mathrm{O}_{2}$ and/or $\mathrm{H}_{2} \mathrm{O}$ can be summarized by three equations 
$\mathrm{CH}_{3} \mathrm{OH}_{\mathrm{g}}+3 / 2 \mathrm{O}_{2} \rightarrow \mathrm{CO}_{2}+2 \mathrm{H}_{2} \mathrm{O}_{\mathrm{g}}$

total oxidation $\quad \Delta_{\mathrm{f}} \mathrm{H}^{\circ}=-676 \mathrm{~kJ} / \mathrm{mol}$

Equation 1

$\mathrm{CH}_{3} \mathrm{OH}_{\mathrm{g}}+1 / 2 \mathrm{O}_{2} \rightarrow \mathrm{CO}_{2}+2 \mathrm{H}_{2}$

partial oxidation $\quad \Delta_{\mathrm{f}} \mathrm{H}^{\circ}=-192 \mathrm{~kJ} / \mathrm{mol}$

Equation 2

$\mathrm{CH}_{3} \mathrm{OH}_{\mathrm{g}}+\mathrm{H}_{2} \mathrm{O}_{\mathrm{g}} \rightarrow \mathrm{CO}_{2}+3 \mathrm{H}_{2}$

reforming $\quad \Delta_{\mathrm{f}} \mathrm{H}^{\circ}=+49 \mathrm{~kJ} / \mathrm{mol}$

Equation 3

The observed ratio of the reaction rates between $\mathrm{H}_{2}$ and $\mathrm{CO}_{2}$ in figure $4 \mathrm{~A}$ is above the stoichiometric ratio of 2 (equation 2 ) and this is due to the presence of gas phase water. Methanol is an excellent hole-scavenger allowing for excited electrons to reduce $\mathrm{H}^{+}$(of surface -OH) to $\mathrm{H}_{2}{ }^{36}$. After e injections into the valence band (VB) methanol gives formaldehyde which in turn is oxidized (with molecular or dissociated oxygen anions radicals) to give $\mathrm{CO}_{2}$ upon further e injections into the $\mathrm{VB}^{37}$. In the presence of water, the reaction gives more $\mathrm{H}_{2}$ (equation 3 ) and the energy needed to drive its reaction (endothermic) is provided from light, in this case. The traces of methane might be due to farther reaction of $\mathrm{CO}_{2}$ with hydrogen atoms ${ }^{38}$. Because Au NRs are caped with an organic compound we have then repeated the experiments in the absence of methanol (blank), to test their possible contribution into the reaction and the results were negative (figure S2). This indicates that $\mathrm{H}_{2}$ and $\mathrm{CO}_{2}$ do not originate from the ligand capping the NRs. Then we have tested the UC material without the semiconductor $\mathrm{CdS}$ but with Au nano-rods. Previous reports have indicated that $\mathrm{Au}$ nanoparticles alone can reduce $\mathrm{H}^{+}$to $\mathrm{H}_{2}$ once excited with visible light ${ }^{39,40,41}$. Indeed the visible light (and probably the 800 nm IR light) both generated by the UC made the reaction possible (with ca. $0.25-0.30$ of the activity obtained when CdS was present). This indicates that $\mathrm{H}_{2}$ production may in part originate from the direct catalytic reaction of the Au NRs upon excitation. The ratio of the production rate of $\mathrm{H}_{2}$ to $\mathrm{CO}_{2}$ in the absence of $\mathrm{CdS}$ is found to be less than 1 . The absence of the semiconductor (absence of energy levels for e transfer from methanol to the VB of CdS) is probably the reason where in this case only hot e from Au NRs are involved in the reaction which in turn makes oxygen anions radicals routes more efficient, generating more $\mathrm{CO}_{2}$ by direct oxidation of methanol. The system does not work in the absence of a metal (since it is needed to trap excited electrons) so one cannot, separately test the extent of enhancement due to Au NRs alone without the addition of another metal such Pd NP, but that is the subject of a separate study. Quantitative quantum yield of the reaction is not possible in our experimental set up, and is most likely very weak. Yet the mere observation of catalytic $\mathrm{H}_{2}$ production indicates that converting IR light to visible light, needed to excite both a visible light driven semiconductor as well as the two plasmonic resonance of $\mathrm{Au}$ nanorods (transverse and longitudinal modes at ca. 500 and $800 \mathrm{~nm}$, respectively, as seen in Figure 2), is possible and can reduce hydrogen ions to molecular hydrogen.

\section{Materials and methodology}

$0.538 \mathrm{~g}$ of Yttrium (III) nitrate hexahydrate (Sigma Aldrich 99+), $0.260 \mathrm{~g}$ of Ytterbium (III) nitrate pentahydrate (Sigma Aldrich 99.9 $\%$ ) and $0.015 \mathrm{~g}$ of Thulium (III) nitrate pentahydrate (Sigma Aldrich $99.9 \%$ ) were dissolved in $75 \mathrm{~mL}$ de-ionized water. $5.777 \mathrm{~g}$ of citric acid was dissolved into the pre-mentioned mixture to obtain a concentration of $0.4 \mathrm{M}$ and citric acid to rare earth metal ratio of 4 . In a separate flask, $3.78 \mathrm{~g}$ of $\mathrm{NaF}$ were dissolved in $75 \mathrm{~mL}$ of deionized water to obtain a $1.2 \mathrm{M}$ concentration. The two mixtures were left under stirring for 1 hour after which, the NaF solution was added to the rare earth metal solution dropwise. After mixing the two solutions, the resulted mixture was left stirring for half an hour then transferred into a Teflon-lined autoclave (where only $3 / 4$ of the autoclave was filled with solution). The solution was then treated hydrothermally at $180^{\circ} \mathrm{C}$ for 24 hours. After completion, the product was washed three times with de-ionized water and once with ethanol.
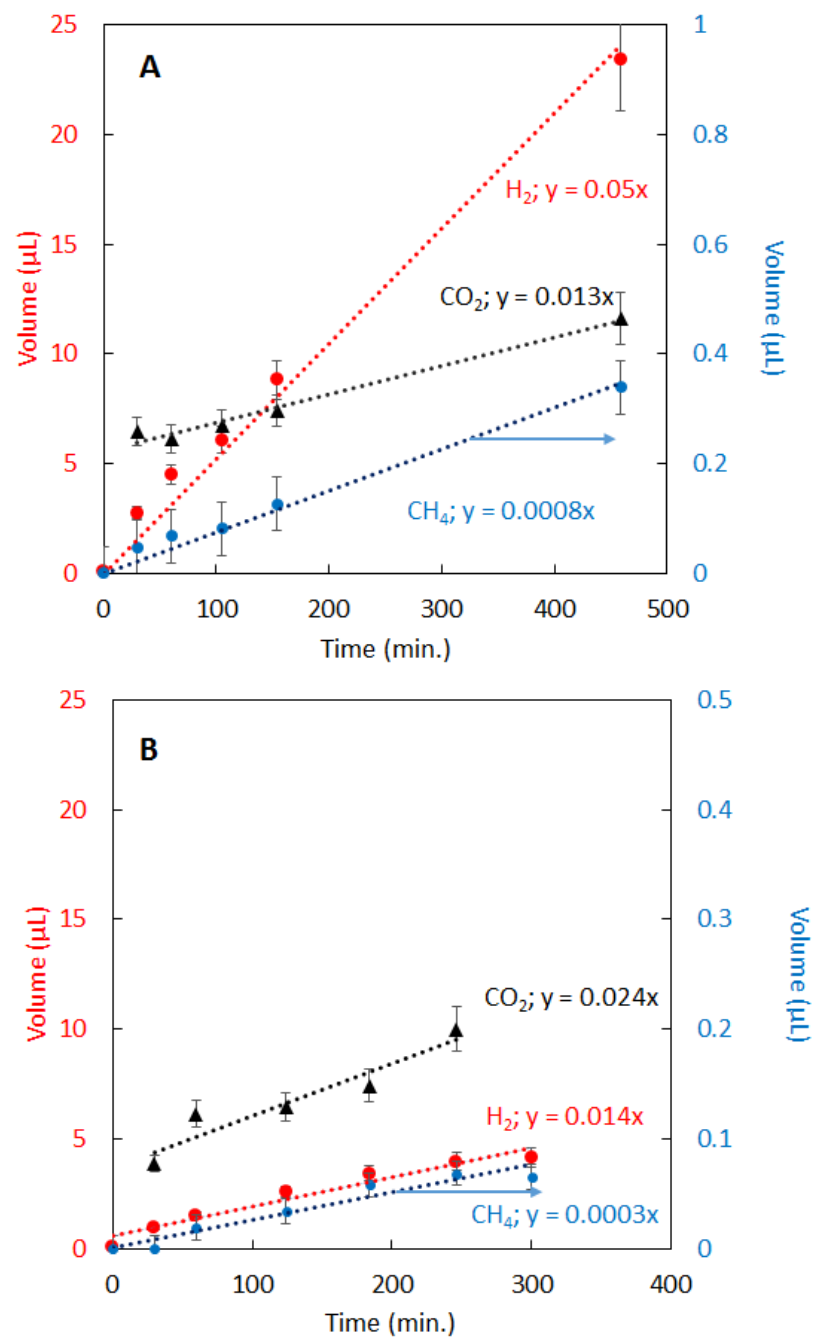

Figure 4

Gas phase photoreaction products of methanol under $980 \mathrm{~nm}$ excitation over A. 0.25 wt. \% Au/CdS)-(NaYF $\left.{ }_{4}-\mathrm{Yb}-\mathrm{Tm}\right)$ with a 1 to 1 ratio. B. 0.25 wt. \% $\mathrm{Au} /\left(\mathrm{NaYF}_{4}-\mathrm{Yb}-\mathrm{Tm}\right)$. Ambient-air + gas phase methanol. Humidity is ca. $50 \%$ at $20^{\circ} \mathrm{C}$, one atm. (ca. $2 \mathrm{kPa}$ ). Methanol vapor pressure is ca. $10 \mathrm{kPa}$. Rates for each product are indicated inside the figure.

\section{$\mathrm{Au} / \mathrm{CdS} /$ Upconverter Preparation}

Gold nanorods colloidal suspension is acquired from Sigma Aldrich with a $10 \mathrm{~nm}$ diameter and $41 \mathrm{~nm}$ in length. Au concentration is estimated to be greater than $30 \mu \mathrm{g} / \mathrm{mL}$ in $\mathrm{H}_{2} \mathrm{O}$. The amount of cetyl trimethylammonium bromide, $\mathrm{C}_{19} \mathrm{H}_{42} \mathrm{NBr}$ (CTAB) ligand on the metal (used to stabilize the nanorods) is estimated to be $<0.1 \mathrm{wt}$. \%. CdS is prepared by precipitation of $\mathrm{Na}_{2} \mathrm{~S}$ and $\mathrm{CdNO}_{3}$ followed by calcination under inert atmosphere at $600^{\circ} \mathrm{C}$ for four hours. 0.25 wt. \% Au/CdS is made by mixing $120 \mathrm{mg}$ of CdS with $10 \mathrm{~mL}$ of gold colloidal suspension and drying at $90^{\circ} \mathrm{C}$ overnight under stirring. 
Photoreaction at $980 \mathrm{~nm}$ Excitation

$15 \mathrm{mg}$ of $0.25 \mathrm{wt}$. \% Au nanorods/CdS are mixed with $15 \mathrm{mg}$ of $\left(\mathrm{NaYF}_{4}-28 \mathrm{~mol} \% \mathrm{Yb}-0.75 \mathrm{~mol} \% \mathrm{Tm}\right)$ and sonicated in ethanol for several minutes. The mixture is then deposited on glass and the solvent dried at $70^{\circ} \mathrm{C}$. Inside a $6 \mathrm{~mL}$ reactor, one drop of methanol (ca. $0.05 \mathrm{~mL}$ to ensure surface saturation) is added along with the coated slide and the reactor is sealed. The catalyst is then excited with 0.15W at $980 \mathrm{~nm}$ (spot size is close to $3 \mathrm{~mm}$ ) light provided from a $100 \mathrm{fs}$ pulsed laser (Coherent), filters were provided from Concept Design Production (CDP) Systems Corp (SF4 contains information related to the filers used). Samples are analyzed by gas chromatography equipped with a thermal conductivity detector and a Hysep $\mathrm{Q}$ column under $\mathrm{N}_{2}$ as a carrier gas. The blank experiment (Figure S2) is conducted in the same manner with the exclusion of methanol to eliminate the possibility of ligand (CTAB) contribution.

Raman analysis were performed using a Thermo Scientific ${ }^{\mathrm{TM}} \mathrm{DXR}^{\mathrm{TM}}$ Raman equipment. Catalyst samples were analysed from 50 to $3400 \mathrm{~cm}^{-1}$ with multiple scans (16scans) with exposure time of 0.5 seconds, the wavelength of the laser used for the analysis was 532 $\mathrm{nm}$, with the power of $8 \mathrm{~mW}$ and the spot size was $2.1 \mu \mathrm{m}$. The aperture opening was $50 \mu \mathrm{m}$ and grating had 900 lines per $\mathrm{mm}$. High-Resolution Transmission Electron Microscopy (HRTEM) was carried out at $200 \mathrm{kV}$ with a JEOL JEM 2100 instrument equipped with a $\mathrm{LaB}_{6}$ source. The point-to-point resolution of the microscope was $0.19 \mathrm{~nm}$. Samples were deposited on holey-carbon-coated $\mathrm{Cu}$ grids from alcohol suspensions.

\section{Acknowledgment}

J.L. is a Serra Húnter Fellow and is grateful to the ICREA Academia Program and MINECO/FEDER grant ENE2015-63969-R.

\section{Notes and references}

${ }^{1}$ Kudo, A; Miseki, Y. Chem. Soc. Rev. 2009, 38, 253-278; and references therein.

${ }^{2}$ Majeed, I.; Amtiaz Nadeem, M.; Al-Oufi, M.; Arif Nadeem, M.; Waterhouse, G.I.N.; Badshah, A.; Metson, J.B.; Idriss, H. Appl. Catal. B. Environ. 2016, 182, 266-276.

${ }^{3}$ Matsumura, M.; Furukawa, S.; Saho, Y.; Omura, H.T.;, J. Phys. Chem. 1985, 89,1327-1329.

${ }^{4}$ Liao, P.; Carter, E. A, Chem. Soc. Rev., 2013, 42, 2401

${ }^{5}$ Fujishima, A.; Zhang, X.; Tryk, D. A. $\mathrm{TiO}_{2}$ photocatalysis and related surface phenomena Surf. Sci. Reports 2008, 63, 515-582.

${ }^{6}$ Chen, X.; Liu, L.; Huang, F.; Chem. Soc. Rev. 2015, 44, 1861-1885.

${ }^{7}$ Su, J.; Vayssieres, L. ACS Energy Lett. 2016, 1, 121-135; and references therein.

${ }^{8}$ Mukherji, A.; Seger, B.; Lu, G.Q.; Wang, L. ACS Nano, 2012, 5, 3483-3492.

${ }^{9}$ Urbain, F.; Smirnov, V.; Becker, J.-P.; Lambertz, A.; Yang, F.; Ziegler, J.; Kaiser, B.; Jaegermann, W.; Rau, U.; Finger, F. Energy Environ. Sci., 2016, 9 , 145-154.
${ }^{10}$ Al-Oufi, M.; Idriss, H. US Patent application Project Number 14T\&I0019US-PSP), filed at the Patent Office on 29-08-2014 as Serial Number 62043859.14T\&I 0019.

${ }^{11}$ Kim, T.W., Choi, K.-S., Science 2014, 343, 990-994.

${ }^{12}$ Sinatra, L.; LaGrow, A.P.; Peng, W.; Kirmani, A.R.; Amassian, A.; Idriss, H. Bakr, O.M. J. Catal. 2015, 322, 109-117.

${ }^{13}$ Hou, W.; Cronin, S. B, Adv. Funct. Mater. 2013, 23, 1612-1619.

${ }^{14} \mathrm{Du}$, L.; Furube, A.; Yamamoto, K.; Hara, K.; Katoh, R.; Tachiya, M. J. Phys. Chem. C 2009, 113, 6454-6462.

${ }^{15}$ Khan, M.A.; Al-Oufi, M.; Sinatra, L.; Bakr, O.M., Idriss, H. Catalysis Letters 2017, 147 (4) 811-820.

${ }^{16}$ Liu, J.; Liu, G.; Li, M.; Shen, W.; Liu, Z.; Wang, J.; Zhao, J.; Jiang, L.; Song, Y. Energy \& Environ. Sci. 2010, 3, 1503-1506.

${ }^{17}$ Boudoire, F.; Toth, R.; Heier, J.; Braun, A.; Constable, E.C. Energy \& Environ. Sci. 2014, 7, 2680-2688

${ }^{18}$ Chen, X., Liu, L., Yu, P. Y., Mao, S.S. Science 2011, 331, 746-750.

${ }^{19}$ Waterhouse, G.I.N., Wahab, A.K.; Al-Oufi, M.; Jovic, V.; Sun-Waterhouse, D.; Anjum, D., A.; Llorca, J.; Idriss, H. Sci. Reports, 2103, 3, 2849 (1-5)

${ }^{20}$ Linic, S.; Christopher, P.; Ingram, D.B.; Nature Mater. 2011, 10, 911-921.

${ }^{21}$ Zhou, J.; Liu, Q.; Feng, W.; Sun, Y.; Li, F. Chem. Rev. 2015, 115, 395-465.

${ }^{22}$ Park, W.; Lu, D.; Ahn, S. Chemical Society Reviews 2015, 44, 2940-2962.

${ }^{23}$ Khan, M.A., Idriss, H. WIREs Energy and Environment, Published Online: Aug 17 2017, DOI: 10.1002/wene.254

${ }^{24}$ X. Pang, Y. He, J. Jung, Z. Lin, Science, 2016, 353, 1268-1272

${ }^{25}$ Vennerberg, D.; Lin, Z., Sci. Adv. Mater. 2011, 3, 26-40.

${ }^{26}$ W. Liao, D. Zheng, J. Tian, Z. Lin, J. Mater. Chem. A, 2015, 3, 23360-23367.

${ }^{27}$ M. He, X. Pang, X. Liu, B. Jiang, Y. He, H. Snaith, Z. Lin, Angew. Chem. Int. Ed. 2016, 55, $4280-4284$.

${ }^{28}$ Auzel, F. Chem. Rev. 2004, 104, 139-174.

${ }^{29}$ Mirza, J., Martens, I., Grüßer, M., Bizzotto, D., Schuster, R., Lipkowski, J. J. Phys. Chem. C, 2016, 120, 16246-16253.

${ }^{30}$ Zhang, X., Chen, Y. L., Liu, R-H., Tsai, D.P., Rep. Prog. Phys. 2013, 76, 046401 1-41.

${ }^{31}$ Lage, M.M., Moreira, R.L., Matinaga, F.M., Gesland, J.-Y., Chem. Mater. 2005, 17, 4523-4529.

${ }^{32}$ Burns, J.H. Inorganic Chem. 1965, 4, 881-886.

${ }^{33}$ Krämer, K.W., Biner, D., Frei, G., Güdel, H.U., Hehlen, M.P., Lüthi, S. R., Chem. Mater. 2004, 16, 1244-1251.

${ }^{34}$ Suyver, J.F., Grimm, J., van Veen, M., Biner, D., Krämer, K., Güdel, H.-U., J. Luminescence, 2006, 117, 1-12.

${ }^{35}$ Rengaraj, S. Venkataraj, S., Jee, S.H., Kim, Y., Tai, C.w., Repo, E., Koistinen, A., Ferancova, A., Sillanpää, M., Langmuir 2010, 27, 352-358.

${ }^{36}$ Al-Azri, Z.H.N., Chan, A., Chen, W.-T., Ina, T., Idriss, H., Waterhouse, G.I.N. J. Catal. 2015, 329, 355-367.

${ }^{37}$ Chen, T., Feng, Z., Wu, G., Shi, J., Ma, G., Ying, P., Li, C., J. Phys. Chem. C 2007, 111, 8005-8014.

${ }^{38}$ H.-A Park, J. H. Choi, K. M. Choi, D. Ki Lee, J. K. Kang, J. Mater. Chem. 2012, 22, 5304-5307.

${ }^{39}$ Scott, K. Cushing, S.K, Li, J., Meng, F., Senty, T.R., Suri, S., Zhi, M., Li, M., Bristow, A. D., Wu, N., J. Am. Chem. Soc. 2012, 134, 15033-15041.

${ }^{40}$ Robatjazi, H., Bahauddin, S. H., Doiron, C., Thomann, I., Nano Lett. 2015, 15, 6155-6161.

${ }^{41}$ Lee, J., Mubeen, S., Ji, X., Stucky, G.D., Moskovits, M. Nano Lett., 2012, 12, 5014-5019. 